\title{
INTERFACIAL REACTIONS BETWEEN THIN FILMS OF ZINC AND (100) InP*
}

\author{
E. Kamińska, A. Piotrowska, A. Barcz \\ Institute of Electron Technology, Al. Lotników 32/46, 02-668 Warszawa, Poland \\ E. Mizera and E. Dynowska \\ Institute of Physics, Polish Academy of Sciences \\ Al. Lotników 32/46, 02-668 Warszawa, Poland \\ The effects of interaction between thin films of $\mathrm{Zn}$ and (100)InP were \\ studied with secondary ion mass spectrometry, X-ray diffraction and trans- \\ mission electron microscopy. Zn was found to penetrate the native oxide on \\ InP surface during deposition and to form an ohmic contact when deposited \\ on highly doped $n$-type InP. Heat treatment causes the formation of $\mathrm{Zn}_{3} \mathrm{P}_{2}$ \\ phase lattice matched to InP.
}

PACS numbers: $73.40 . \mathrm{Ns}$

Zinc is currently being used as a dopant element in ohmic contact metallizations to $p$-type III-V compound semiconductors. A low contact resistivity of $\mathrm{Zn}$-containing contacts is attributed to a diffusion of $\mathrm{Zn}$ atoms, resulting in a highly doped interface layer. The results of our recent study on $\mathrm{Zn}$-based metallizations to $p$-GaAs, however, strongly suggest that $\mathrm{Zn}$ plays a more fundamental role in the formation of an ohmic contact. When deposited directly onto GaAs, Zn penetrates the native oxide [1]. Added to Au metallization lowers the temperature of reaction between $\mathrm{Au}$ and GaAs. Furthermore, $\mathrm{Zn}$ stabilizes the size of metallization grains $[2,3]$.

In this work we focus on the reactivity of thin $\mathrm{Zn}$ films deposited on InP in order to determine to what extent the interaction of zinc with native oxides can be generalized to other compound semiconductors. We study structural and electrical properties of the contacts using XRD (X-ray diffraction), TEM (transmission electron microscopy), SIMS (secondary ion mass spectrometry), and specific contact resistance measurements.

Conventional TEM and high resolution electron microscopy (HREM) investigations were made on cross-sectional specimens, with [110] InP normal to the surface, prepared by a standard technique with the final iodine ion milling. SIMS profiling was carried out using $\mathrm{Cs}^{+}$as a primary beam with detection of $\mathrm{CsM}_{i}^{+}$ secondary cluster ions, enabling thus determination of the relative concentration

*This work is supported by the U.S.-Polish Maria Skłodowska-Curie Joint Fund II MP/NASA-95-230. 
of the sample constituents $M_{i}$ with reduced matrix eflects. Such configuration, together with the pressure in the analysis chamber of the order of $10^{-10} \mathrm{Tr}$ makes it possible to simultaneously monitor different species e.g. oxygen and indium.

Zn films, 200 to $1100 \mathrm{~nm}$ thick, were vacuum deposited on (100) oriented InP. The single crystal substrates were either $p$-type doped with $\mathrm{Zn}(p=$ $\left.4 \times 10^{18} \mathrm{~cm}^{-3}\right)$ or $n$-type undoped and doped with $\mathrm{S}\left(n=5 \times 10^{15}\right.$ $\left.1 \times 10^{18} \mathrm{~cm}^{-3}\right)$. Prior to metal deposition the surface of $\mathrm{InP}$ was processed in hot organic solvents, etched in $\mathrm{HCl}: \mathrm{CH}_{3} \mathrm{COOII}: \mathrm{H}_{2} \mathrm{O}_{2}(1: 2: 1)$, rinsed in $\mathrm{H}_{2} \mathrm{O} \mathrm{DI}$, and dipped for $15 \mathrm{~s}$ in $\mathrm{NI}_{4} \mathrm{OII}: \mathrm{II}_{2} \mathrm{O}(1: 10)$. The samples were annealed under flowing hydrogen for 3 to $10 \mathrm{~min}$ at temperatures in the range from 200 to $400^{\circ} \mathrm{C}$.

(a)

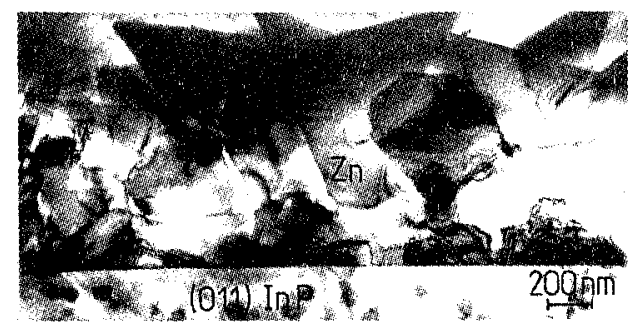

(b)
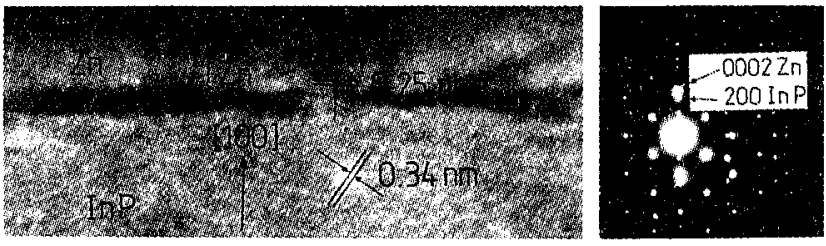

(c)

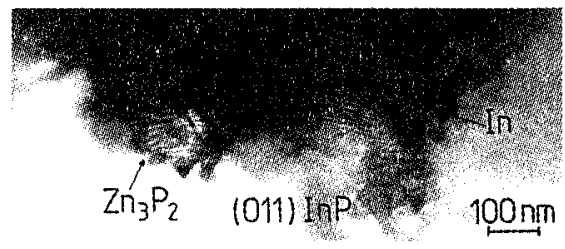

(d)
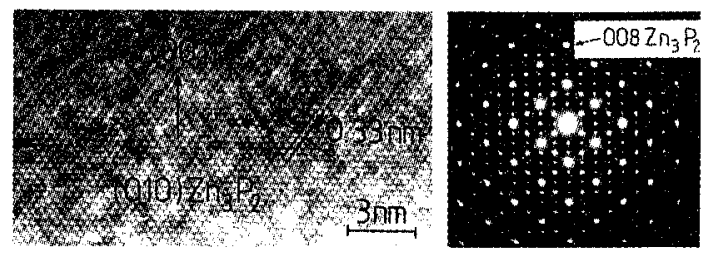

Fig. 1. (011) transmission electron micrograph of $\mathrm{Zn} / \mathrm{InP}$ contact: (a) as deposited contact, (b) HREM lattice image and corresponding SAD (selected area diffraction) pattern of the as deposited contact, (c) contact annealed at $320^{\circ} \mathrm{C}$ for $3 \mathrm{~min}$, (d) HREM lattice image of $\mathrm{Zn}_{3} \mathrm{P}_{2}$ phase. 


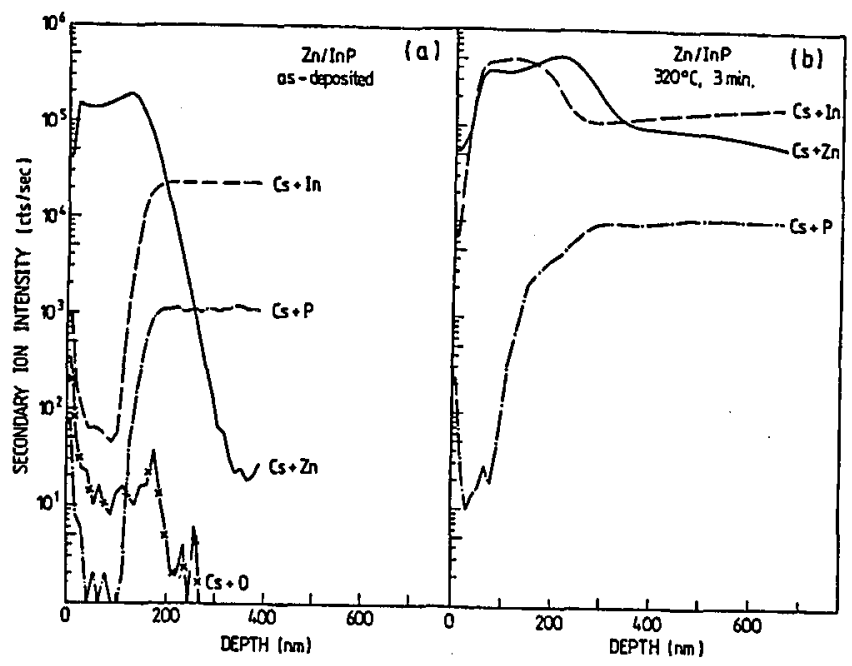

Fig. 2. SIMS in-deptl profiles from $\mathrm{Zn} / \mathrm{InP}$ contact: (a) as deposited, (b) annealed at $320^{\circ} \mathrm{C}$ for $3 \mathrm{~min}$.

Upon deposition $\mathrm{Zn}$ forms large, irregularly shaped grains $(200 \times 600 \mathrm{~nm})$. Figure 1a shows the $\mathrm{Zn} / \mathrm{InP}$ interface at low magnification demonstrating the polycrystalline nature and distinct grains of the metallization. Most of these grains are epitaxial with their $(01 \overline{1} 0)_{\mathrm{Z}_{\mathrm{n}}}$ or $(2 \overline{1} \overline{1} 0)_{\mathrm{Zn}}$ orientation parallel to the (011) InP orientation, and $[0001]_{\mathrm{Zn}} \|[100]_{\mathrm{InP}}$. The interface is abrupt, smooth and displays no evidence of an interfacial oxide. Zinc is in intimate contact with the substrate, which is clearly seen in the high resolution image (Fig. 1b). SIMS profiles for the as-deposited $\mathrm{Zn} / \mathrm{InP}$ contacts, displayed in Fig. 2a, clearly demonstrate the ability of $\mathrm{Zn}$ to permeate the oxide layers.

As a result of annealing at around $200^{\circ} \mathrm{C}$, the interface roughens. Triangular protrusions, with sides delineated by InP $\{111\}$ planes form (Fig. 1c). A tetragonal $\mathrm{Zn}_{3} \mathrm{P}_{2}$ phase with $a=0.8113 \mathrm{~nm}$ and $c=1.147 \mathrm{~nm}$ was identified by electron and $\mathrm{X}$-ray difraction. $\mathrm{Zn}_{3} \mathrm{P}_{2}$ is lattice matched to $\mathrm{InP}$ with the orientation relationships: $(010)_{\mathrm{Zn}_{3} \mathrm{P}_{2}} \|(011)_{\mathrm{InP}}$ and $[001]_{\mathrm{Zn}_{3} \mathrm{P}_{2}} \|[100]_{\mathrm{InP}}$ (Fig. 1d). At higher temperatures and longer annealing times, this phase penetrates deeply into the substrate.

The formation of a binary compound which contains $\mathrm{Zn}$ and $\mathrm{P}$ results in an cxcess number of In atoms. In fact, an important intermixing between $\mathrm{Zn}$ and $\mathrm{InP}$ accompanied by outdiffusion of In into the metallic layer is evidenced by SIMS depth profiling of the heat treated ccitact (Fig. 2b). Also TEM analysis shows the formation of crystalline In inclusions in the $\mathrm{Zn}$ layer in the vicinity of the $\mathrm{Zn}_{3} \mathrm{P}_{2}$ phase protrusions (Fig. 1c).

Electrical measurements show that $\mathrm{Zn} / p$-InP contacts, in contrast to $\mathrm{Zn} / p$-GaAs ones, are not ohmic. Instead, $\mathrm{Zn}$ deposited on $n$-type doped $(n=$ $7 \times 10^{17} \mathrm{~cm}^{-3}$ ) InP does exhibit linear $I-V$ characteristics. Even if the resistivity of such a system is relatively high $\left(4.4 \times 10^{-4} \Omega \mathrm{cm}^{2}\right)$, this observation seems to contradict the generally accepted opinion according to which ohmic behaviour of 
$\mathrm{Zn}$-containing contacts is ascribed to the formation of a $p^{+}$layer.

We postulate that assuring appropriate penetration of the metal through the native oxide together with a close matching to the semiconductor surface may play a fundamental role in the formation of an ohmic contact.

\section{References}

[1] E. Kamińska, A. Piotrowska, R. Żarecka, A. Barcz, E. Mizera, Acta Phys. Pol. A 84, 527 (1993).

[2] E. Kamińska, A. Piotrowska, E. Mizera, R. Żarecka, J. Adamczewska, E. Dynowska, Mater. Res. Soc. Symp. Proc. 300, 237 (1993).

[3] E. Kaminiska, A. Piotrowska, E. Mizera, A. Dynowska, Thin Solid Films 246, 143 (1994). 